\title{
PU゚VOD FLUID PRIMÁRNÍ ZLATONOSNÉ MINERALIZACE V HORÁCH U PŘEDÍNA (ZÁPADNÍ MORAVA)
}

\author{
Origin of fluids of primary auriferous mineralization at Hory near Předín (western Moravia) \\ Tereza Potočková', Zdeněk Dolníček', Stanislav Houzar² \\ ${ }^{1}$ Katedra geologie PřF UP, 17. listopadu 12, 771 46 Olomouc; e-mail: Tereza.Potockova@seznam.cz \\ ${ }^{2}$ Mineralogicko-petrografické oddělení, Moravské zemské muzeum, Zelný trh 6, 65937 Brno
}

(23-43 Telč)

Key words: Moldanubicum, auriferous quartz veins, oxygen isotopes, crush-leach analyses, fluid inclusions

\begin{abstract}
Isotopic analyses of oxygen and crush-leach analyses of fluid inclusions were applied to quartz gangue from auriferous mineralization at three localities in the vicinity of Hory near Předín („Zákopy“, „Štůlně“, and „Malý Štitek“). Oxygen isotope composition of the ore-forming fluids varies between -8.1 and $+0.9 \%$ SMOW. Dominant anion in fluid inclusions is $\mathrm{Cl}$, whereas $\mathrm{Ca}, \mathrm{K}$, and $\mathrm{Na}$ are predominant cations. The halogen molar ratios are rather variable $\left(\mathrm{Br} / \mathrm{Cl}=0.8-2.110^{-3} ; \mathrm{I} / \mathrm{Cl}=34-34110^{-6}\right)$. The variability in composition of fluids is probably caused by mixing of several genetic types of water. It is supposed that the main source of oreforming fluids is meteoric water which has typically negative $\delta^{18} O$ values. This type of water mixed with fluids which are related to evaporation of seawater, dissolution of evaporites, magmatogenic water and/or shield brines.
\end{abstract}

\section{Úvod}

V okolí obce Hory u Předína (západní Morava) se nacházejí pozůstatky po středověkém dobývání zlata na třech dílčích lokalitách - Štůlně, Zákopy a Malý Štítek (Koutek 1924). Z ložiskově-geologického hlediska byla tato oblast doposud nejpodrobněji zhodnocena v obsáhlé nepublikované závěrečné zprávě Veselého et al. (1988), zahrnující jak studium primárního ložiska, tak i výsledky šlichové prospekce. Historicko-montanistickou problematiku oblasti, doplněnou o řadu nových poznatkủ mineralogicko-geologické povahy, uveřejnil Vokáč et al. (2008). Mineralogií a studiem podmínek vzniku zdejší Au-mineralizace včetně výzkumu fluidních inkluzí pomocí optické mikrotermometrie se zabývá práce Potočkové et al. (2010).

Studovaná oblast (okolí Hor u Předína, asi $20 \mathrm{~km}$ západně od Třebíče) se nachází z regionálně-geologického hlediska v moldanubiku západní Moravy (Dudek et al. 1992). Biotitické a sillimanit-biotitické pararuly, které představují základní horniny oblasti, jsou doprovázeny četnými vložkami světlých kvarcitů, dále také amfibolitů, serpentinitů, amfibolizovaných eklogitů a vápenatosilikátových hornin. Vzácnější jsou turmalín-muskovitické metagranity (ortoruly) a žíly pegmatitů.

Pravé křemenné žíly, na něž je vázáno zlatonosné zrudnění, protínají převážně biotitické pararuly a kvarcity ve směru VJV-ZSZ a JV-SZ, popř. V-Z; lokálně se v kvarcitech vyskytují i menši žilníky (Veselý et al. 1988, Vokáč et al. 2008). Studované okolí Hor se vyznačuje poměrně jednoduchou zlatonosnou mineralizací (pyrit $>>$ zlato (až elektrum), velmi vzácně akantit, galenit, chalkopyrit, bliže neurčená NiAsS fáze; Malec 1988, Veselý 1992, Potočková et al. 2010). Žilovina je tvořena křemenem, v němž byly studovány fluidní inkluze metodou optické mikrotermometrie (Potočková et al. 2010). Na základě získaných dat autoři předpokládají magmatický nebo pozdně (retrográdně?) metamorfní původ fluid systému $\mathrm{H}_{2} \mathrm{O}-\mathrm{MgCl}_{2}-\mathrm{NaCl}$ s celkovou salinitou 2,4-9,9 hm. \% $\mathrm{NaCl}$ ekv. Teploty homogenizací se pohybují v rozmezí $129-259^{\circ} \mathrm{C}$ u primárních inkluzí.

Předkládaný př́spěvek je věnován studiu výluhů fluidních inkluzí a izotopového složení kyslíku v křemeni. Jeho záměrem je doplnit poznání o první izotopová data a diskutovat možný původ hydrotermálních roztoků, z nichž byla Au-mineralizace formována.

\section{Metodika}

Během terénního výzkumu a dokumentace lokalit v letech 2008-2011 byly odebrány vzorky křemenné žiloviny, z níž byly nejdříve vyhotoveny výbrusy, které byly následně vyhodnoceny v optické laboratoři Katedry geologie PřF UP Olomouc na polarizačním mikroskopu Olympus v procházejícím i odraženém světle. Dále byly vyhotoveny oboustranně leštěné destičky z pěti vzorků křemenné žiloviny pro studium fluidních inkluzí optickou mikrotermometrií, jejižz výsledky jsou publikovány v práci Potočkové et al. (2010). Následně byly stejné vzorky použity na analýzu výluhů $z$ fluidních inkluzí. Jedná se o tyto vzorky: $2 \times$ Štůlně, $1 \times$ Malý Štítek, $2 \times$ Zákopy, které byly podrceny na požadovanou frakci $0,3-1,1 \mathrm{~mm}$ a poté povařeny

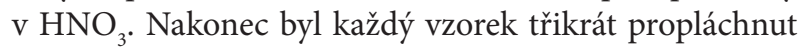
a povařen ve vodě a posléze ještě trikikrát $\mathrm{v}$ destilované vodě, popr. byly po usušení ze vzorku ručně vybrány zbývající viditelné nečistoty. $Z$ usušených vzorkủ bylo odváženo požadované množství minimálně $1 \mathrm{~g}$. Příprava a analýza výluhů byla provedena prof. W. Prochaskou v laboratořích univerzity v Leobenu. Jeden gram vysušeného vzorku byl rozetřen $\mathrm{v}$ achátové třecí misce $\mathrm{s} 5 \mathrm{ml}$ deionizované vody. Vzniklá suspenze byla přefiltrována přes nylonový filtr o velikosti pórů $0,2 \mu \mathrm{m}$. Anionty byly stanoveny pomocí systému Dionex (DX-500) a kationty pomocí standardní 
atomové emisní spektrometrie. Stejné vzorky žiloviny a navíc vzorky kvarcitu z lokality Hory - Zákopy byly použity na analýzu izotopového složení kyslíku, kterou provedl v laboratořích Institutu mineralogie a geochemie Univerzity v Lausanne dr. B. Putlitz. Př́prava vzorků pro tuto analýzu byla shodná s př́pravou pro analýzu výluhů (viz výše). Množství 0,5-2 mg vzorku bylo rozloženo působením elementárního fluoru po zahřátí $\mathrm{CO}_{2}$ - laserem. Přebytečný $\mathrm{F}_{2}$ byl odstraněn od získaného kyslíku pomocí $\mathrm{KCl}$ při $150^{\circ} \mathrm{C}$. Izotopové složení extrahovaného kyslíku bylo po jeho přečištění na molekulovém sítu ( $5 \AA$ ) změřeno

\begin{tabular}{|c|c|c|c|c|c|}
\hline číslo vzorku & popis vzorku & lokalita & $\begin{array}{c}\boldsymbol{\delta}^{18} \mathbf{O}_{\text {quartz }} \\
(\% \text { SMOW })\end{array}$ & $\begin{array}{c}\boldsymbol{\delta}^{18} \mathbf{O}_{\text {fluid }} \\
(\% \text { SMOW })\end{array}$ & $\begin{array}{c}\mathrm{T}_{\mathrm{h}}(\mathrm{P}-\mathrm{FI}) \\
\left({ }^{\circ} \mathrm{C}\right)\end{array}$ \\
\hline 2 & křemen & Štůlně & 9,4 & $-8,1$ až $-2,8$ & $130-192$ \\
\hline $7 \mathrm{a}$ & křemen & Zákopy & 10,2 & $-2,5$ až 0,2 & $184-228$ \\
\hline 9 & křemen & & 9,4 & $-6,5$ až 0,9 & $146-260$ \\
\hline 8 & křemen & Malý Štítek & 10,8 & $-4,7$ až $-0,4$ & $150-207$ \\
\hline $7 \mathrm{~b}$ & kvarcit & Zákopy & 13,5 & & \\
\hline
\end{tabular}

Tab. 1: Výsledky analýzy izotopového složení kyslíku v křemenné žilovině z Hor. K přepočtu výsledků na izotopové složení fluid byly použity hodnoty $\mathrm{T}_{\mathrm{h}}$ primárních fluidních inkluzí.

Tab. 1: The results of analysis of oxygen isotopic composition in quartz gangue from Hory. The $\mathrm{T}_{\mathrm{h}}$ values of primary fluid inclusions were used to convert the quartz $\delta^{18} \mathrm{O}$ data to isotopic composition of hydrothermal fluids.
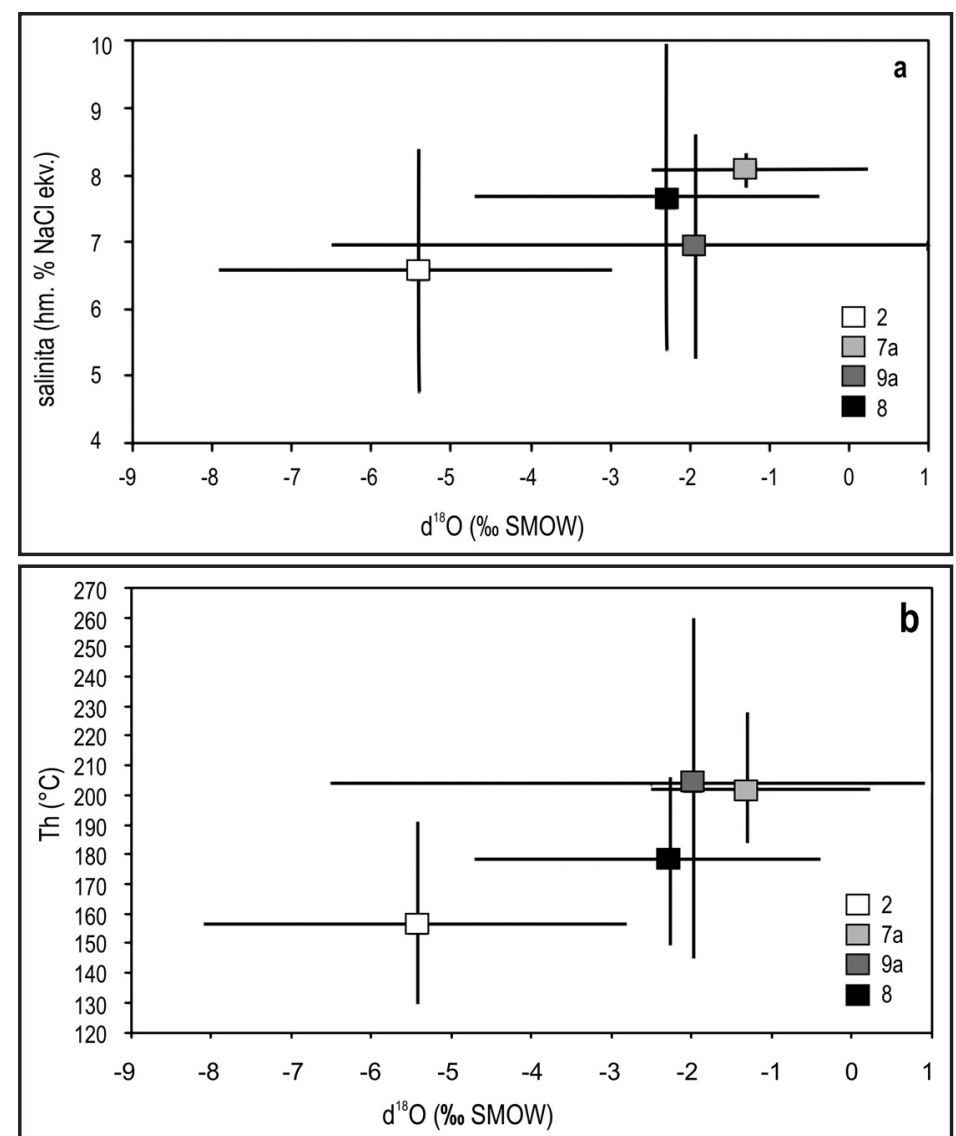

Obr. 1: a - Graf závislosti $\delta^{18} \mathrm{O}$ fluid na salinitě hydrotermálních roztoků $\mathrm{v}$ křemenu $\mathrm{z}$ Hor; $\mathrm{b}$ - Graf závislosti $\delta^{18} \mathrm{O}$ fluid na $\mathrm{T}_{\mathrm{h}}$ primárních fluidních inkluzí. V grafu jsou vyneseny průměrné hodnoty, čáry vyznačují rozsah hodnot $\delta^{18} \mathrm{O}, \mathrm{T}_{\mathrm{h}}$ a salinity.

Fig. 1: a - Relationship between fluid $\delta^{18} \mathrm{O}$ and salinity of the hydrothermal fluids in quartz gangue from Hory; $\mathrm{b}$ - relationship between fluid $\delta^{18} \mathrm{O}$ and $\mathrm{T}_{\mathrm{h}}$ of primary fluid inclusions. Data points represent average values of $\delta^{18} \mathrm{O}$, $\mathrm{T}_{\mathrm{h}}$, and salinity, bars represent range of $\delta^{18} \mathrm{O}, \mathrm{T}_{\mathrm{h}}$, and salinity. pomocí hmotnostního spektrometru Finnigan MAT 253. Průměrná přesnost měření je lepší než $\pm 0,2 \%$.

\section{Izotopové složení kyslíku}

Získané hodnoty izotopového složení kyslíku (+9,4 až +10,8 \%o SMOW) pro křemennou žilovinu byly přepočteny dle Zhenga (1993) na izotopové složení fluid (viz tab. 1). $\mathrm{K}$ přepočtu byly využity dříve získané teploty homogenizací primárních fluidních inkluzí v daných vzorcích (Potočková et al. 2010). Izotopové složení kyslíku fluid, z nichž vznikla Au-mineralizace, je poměrně variabilní a pohybuje se v rozmezí $-8,1$ až $+0,9 \%$ SMOW. Pro identifikaci možných trendů ve složení fluid byly sestaveny grafy závislosti $\delta^{18} \mathrm{O}$ na salinitě fluid a na $\mathrm{T}_{\mathrm{h}}$ (teploty homogenizace, obr. $1 \mathrm{a}$, b). Lze z nich vypozorovat trend míšení dvou typů fluid. Jedná se o míšení fluida s nízkými hodnotami $\delta^{18} \mathrm{O}$, nižší salinitou a nižšími hodnotami $\mathrm{T}_{\mathrm{h}}$ a na druhé straně fluida $s$ vyššími hodnotami $\delta^{18} \mathrm{O}$, relativně vyšší salinitou a vyššími hodnotami $\mathrm{T}_{\mathrm{h}}$.

Vypočtené izotopové složení kyslíku fluid se pohybuje téměř výhradně v záporných hodnotách, což dovoluje předpokládat meteorickou vodu jako hlavní zdroj fluid (Craig 1961, Hoefs 2004). Např. Novák et al. (2005) uvádí složení kyslíku současné meteorické vody v ČR v rozmezí -9 až - $11 \%$ o SMOW. Vzhledem $\mathrm{k}$ poměrně širokému rozptylu hodnot $\delta^{18} \mathrm{O}$ (až do mírně kladných hodnot) lze předpokládat, že se jedná o složitější systém, kde se míchá více genetických typů vod. Jako možné varianty vod mísících se s vodou meteorickou lze uvažovat vodu mořskou, pro niž jsou však charakteristické nulové hodnoty $\delta^{18} \mathrm{O}$. Dále lze předpokládat účast vody magmatického či metamorfního původu $\left(\delta^{18} \mathrm{O}\right.$ pro magmatickou vodu dle Hoefse $2004+6$ až $+10 \%$ SMOW a pro metamorfní vodu dle Taylora $1974+5$ až +25\% SMOW). Této domněnce nasvědčují i trendy patrné $\mathrm{z}$ obr. $1 \mathrm{a}, \mathrm{b}$.

\section{Chemické složení výluhů fluidních inkluzí}

$\mathrm{Z}$ výsledků analýzy výluhů je patrné, že dominujícím aniontem ve všech vzorcích je $\mathrm{Cl}^{-}$, zatímco z kationtů převažuje $\mathrm{Ca}^{2+}, \mathrm{K}^{+}$a $\mathrm{Na}^{+}$ (tab. 2). Molární poměry $\mathrm{Br} / \mathrm{Cl}$ a I/Cl vykazují poměrně širokou variabilitu $(\mathrm{Br} / \mathrm{Cl}=0,8-2,1$ $\times 10^{-3} ; \mathrm{I} / \mathrm{Cl}=34-341 \times 10^{-6} ;$ tab. 2). Stejně tak byly vypočteny molární poměry $\mathrm{Ca} / \mathrm{Na}, \mathrm{K} / \mathrm{Na}$ a Li/Na (tab. 2). Molární poměry halogenů byly vyneseny do diagramu spolu s dalšími srovnávacími daty $\mathrm{z}$ různých geologických prostředí (obr. 2). Poměry halogenů fluidních inkluzí z Hor jsou srovnatelné s fluidy pocházejícími z Au-žil na lokalitě Mokrsko a z vysoce 


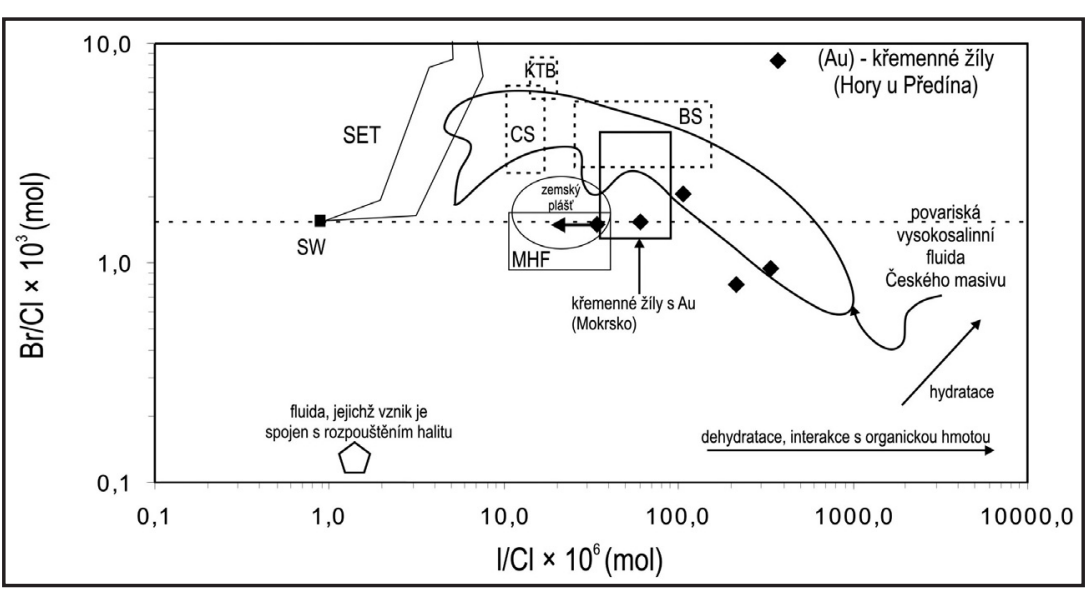

Obr. 2: Diagram I/Cl vs. $\mathrm{Br} / \mathrm{Cl}$ výluhů fluidních inkluzí z Hor u Předína a jejich srovnání s fluidy různého původu (upraveno podle Dolníčka et al. 2009, data pro Mokrsko převzata z Boiron et al. 2001). SW mořská voda, SET linie evaporace mořské vody, MHF nekontaminovaná magmatická hydrotermální fluida, CS solanky z kanadského štítu, BS solanky z baltického štítu, KTB hlubinné solanky navrtané vrtem KTB (Bavorsko). $\longleftrightarrow$ šipka značí směr skutečného umístění daného bodu (jód pod mezí stanovitelnosti).

Fig. 2: $\mathrm{I} / \mathrm{Cl}$ vs. $\mathrm{Br} / \mathrm{Cl}$ plot of fluid inclusions leachates from Hory near Předín and comparison with fluids of various origins (modified from Dolníček et al. 2009, data from Mokrsko gold deposit were taken from Boiron et al. 2001), SW seawater, SET seawater evaporation trajectory, MHF uncontaminated magmatic hydrothermal fluids, CS shield brines from the Canadian Shield, BS shield brines from the Baltic Shield, KTB deep brines drilled by KTB borehole (Bavaria, Bohemian Massif). $\longleftrightarrow$ arrow indicates direction of real position of the given data point (iodine under the detection limit).

salinních povariských fluid v Českém masivu. Data však nespadají výhradně do žádné z možných genetických kategorií (srov. obr. 2) a lze tedy uvažovat o těchto možnostech:

1. Poměry $\mathrm{Br} / \mathrm{Cl}$ a I/Cl mají hodnoty výrazně odlišné od hodnot mořské vody, pouze dvě analýzy mají stejný molární poměr $\mathrm{Br} / \mathrm{Cl}$, ale výrazně vy̌ší $\mathrm{I} / \mathrm{Cl}$. Mořskou vodu však nelze zcela vyloučit vzhledem $\mathrm{k}$ trendu zvyšo-

\begin{tabular}{|l|c|c|c|c|c|}
\hline \multicolumn{1}{|c|}{ lokalita } & Štůlně & $\begin{array}{c}\text { Malý } \\
\text { Štítek }\end{array}$ & \multicolumn{3}{|c|}{ Zákopy } \\
\hline č́slo vzorku & 2 & 8 & 7 & 9 & 10 \\
\hline $\mathrm{Li}$ & 34 & 56 & 43 & 28 & 42 \\
\hline $\mathrm{Na}$ & 519 & 574 & 702 & 970 & 461 \\
\hline $\mathrm{K}$ & 1004 & 356 & 554 & 512 & 380 \\
\hline $\mathrm{Mg}$ & 202 & 61 & 22 & 39 & 7 \\
\hline $\mathrm{Ca}$ & 3249 & 979 & 442 & 883 & 169 \\
\hline $\mathrm{F}$ & 39 & 23 & 22 & 10 & 14 \\
\hline $\mathrm{Cl}$ & 460 & 307 & 712 & 821 & 307 \\
\hline $\mathrm{Br}$ & 0,8 & 0,7 & 2,4 & 2,8 & 1,4 \\
\hline $\mathrm{I}$ & 0,4 & 0,4 & 0,2 & $<0,1$ & 0,1 \\
\hline $\mathrm{NO} \mathrm{S}_{3}$ & 367 & 678 & 298 & 448 & 150 \\
\hline $\mathrm{SO} \mathrm{H}_{4}$ & 96 & 81 & 76 & 309 & 60 \\
\hline $\mathrm{Br} / \mathrm{Cl} 10^{3}$ & 0,8 & 0,9 & 1,5 & 1,5 & 2,1 \\
\hline $\mathrm{I} / \mathrm{Cl} 10^{6}$ & 215 & 341 & 60 & $<34$ & 107 \\
\hline $\mathrm{K} / \mathrm{Na}$ & 1,1 & 0,4 & 0,5 & 0,3 & 0,5 \\
\hline $\mathrm{Ca} / \mathrm{Na}$ & 3,2 & 2,7 & 0,8 & 1,7 & 0,4 \\
\hline $\mathrm{Li} / \mathrm{Na}$ & 0,2 & 0,3 & 0,2 & 0,1 & 0,3 \\
\hline
\end{tabular}

Tab. 2: Výsledky chemické analýzy výluhů fluidních inkluzí $\mathrm{v}$ křemenu ( $\mathrm{v} \mathrm{ppb})$ a vypočítané molární poměry halogenů a vybraných kationtů.

Tab. 2: The results of crush-leach analyses of fluid inclusions in quartz (in ppb) and calculated molar ratios of halogens and selected cations. vání poměrů $\mathrm{I} / \mathrm{Cl}$ vlivem interakce s organickou hmotou (viz obr. 2). Práce Kř́bka et al. (2009), zabývající se podmínkami vzniku uranové mineralizace na ložisku Rožná (strážecké moldanubikum), doložila interakci povariských hydrotermálních roztokủ s organickou hmotou nemetamorfovaných sedimentárních hornin povariského sedimentárního pokryvu moldanubika.

2. Magmatická fluida, uvolněná při krystalizaci magmatu. $\mathrm{V}$ obr. 2 jsou uvedeny rozsahy hodnot poměrů halogenů pro nekontaminovaná magmatická hydrotermální fluida a lze konstatovat shodu nebo podobnost některých analýz z Hor s charakteristikami těchto fluid. Tento typ fluid nelze zcela vyloučit vzhledem k tomu, že zájmová lokalita se nachází mezi dvěma významnými tělesy granitoidních hornin moldanubika (trřebičský masiv a centrální moldanubický pluton).

3. Další možností jsou tzv. „štítové solanky“ zahrnující i solanky Českého masivu (např. Pačes 1987). Tyto solanky vykazují zvýšené poměry $\mathrm{Br} / \mathrm{Cl}\left(3,510^{-3}\right.$ až $\left.6,510^{-3}\right)$. Molární poměry I/Cl vykazují hodnoty mezi $1010^{-6}$ a $10010^{-6}$ (obr. 2). Původ těchto fluid je hledán $\mathrm{v}$ in-situ nízkoteplotních interakcích srážkové vody a hornin krystalinika, může však jít i o diageneticky modifikované fosilní mořské vody (Bottomley et al. 2002).

4. Posledním uvažovaným typem jsou fluida, jejichž vznik je spojen s vypařováním mořské vody nebo s rozpouštěním evaporitů (Carpenter 1978, Fontes a Matray 1993). Evaporací mořské vody vznikají solanky se zvýšenými hodnotami $\mathrm{Br} / \mathrm{Cl}$ a I/Cl. Je to vysvětlováno tím, že do krystalové struktury chloridů vstupuje při jejich srážení jen velmi malé množství bromu a jódu (tyto prvky zůstávají ve zbytkovém roztoku). Rozpouštění evaporitů způsobuje vznik solanek s velmi nízkými poměry $\mathrm{Br} / \mathrm{Cl}$. Ke zvyšování molárních poměrů I/Cl může dojít i vlivem pozdější interakce fluid s organickou hmotou, která je silně obohacena o jód (Muramatsu a Wedepohl 1998, obr. 2).

\section{Závěry}

Ze všech diskutovaných možností lze považovat za dominantní zdroj fluid meteorickou vodu. Avšak vzhledem $\mathrm{k}$ poměrně variabilnímu složení roztokủ v Horách, at už se jedná o izotopové složení kyslíku či poměry halogenů, se nejedná o jednosložkový systém. Meteorická voda se zde míchala s dalším minimálně jedním genetickým typem fluid. Lze předpokládat, že mohlo dojít k interakci se solankami vznikajícími vypařováním mořské vody a rozpouštěním evaporitů. Zvýšené hodnoty I/Cl lze vysvětlit interakcí s organickou hmotou, naopak nižší hodnoty $\mathrm{Br} /$ $\mathrm{Cl}$ jsou pravděpodobně způsobeny rozpouštěním evapo- 
ritů. Na složení hydrotermálních fluid se mohly podílet i roztoky magmatického původu nebo tzv. štítové solanky (viz obr. 2).

\section{Poděkování}

Autoři děkují prof. W. Prochaskovi za analýzu výluhů fluidních inkluzí a dr. B. Putlitz za analýzu izotopového složení kyslíku v křemenu. Práce je součástí projektu IGA UP PrF/2011/010 „Fluidní systémy moldanubika“ a souvisí částečně s problematikou řešenou mineralogicko-petrografickým odd. Moravského zemského muzea jako výzkumné organizace MK 000094862.

\section{Literatura}

Boiron, M. Ch. - Barakat, A. - Cathelineau, M. - Banks, D. A. - Durisova, J. - Morávek, P. (2001): Geometry and P-V-T-X conditions of microfissural ore fluid migration: the Mokrsko gold deposit (Bohemia). - Chemical Geology, 173, 207-225.

Bottomley, D. J. - Renaurd, J. - Kotzer, T. - Clark, I. D. (2002): Iodine-129 constraints on residence times of deep marine brines in the Canadian Shield. - Geology, 30, 7, 587-590.

Carpenter, A. B. (1978): Origin and chemical evolution of brines in sedimentary basins. - Oklahoma Geological Survey, $79,60-77$. Craig, H. (1961): Isotopic variations in meteoric waters. - Science, 133, 1702-1 703.

Dolníček, Z. - Fojt, B. - Prochaska, W. - Kučera, J. - Sulovský, P. (2009): Origin of the Zálesí U-Ni-Co-As-Ag/Bi deposit, Bohemian Massif, Czech Republic: fluid inclusion and stable isotope constraints. - Mineralium Deposita, 44, 81-97.

Dudek, A. - Chlupáć, I. - Pouba, Z. - Vejnar, Z. - Zapletal, J. (1992): Krystalinikum a prevariské paleozoikum. - In: Chlupáč, I. - Štorch, P. (eds) Regionálně-geologické dělení Českého masívu na území České republiky. - Časopis pro mineralogii a geologii, 37, 4, 258-275. Praha.

Fontes, J. Ch. - Matray, J. M. (1993): Geochemistry and origin of formation brines from the Paris basin, France: 1. Brines associated with Triassic salts. - Chemical Geology, 109, 149-175.

Hoefs, J. (2004): Stable Isotope Geochemistry. - Springer Verlag, Berlin, Heidelberg.

Koutek, J. (1924): O zlatonosném území v okolí Hor na jihozápadní Moravě. - Časopis Vlasteneckého spolku musejního, 35, 1-2, 1-5. Kř́bek, B. - Žák, K. - Dobeš, P. - Leichmann, J. - Pudilová, M. - René, M. - Scharm, B. - Scharmová, M. - Hájek, A. - Holeczy, D. - Hein, U. F. - Lehmann, B. (2009): The Rožná uranium deposit (Bohemian massif, Czech Republic): shear zone-hosted, late Variscan and post-Variscan hydrothermal mineralization. - Mineralium Deposita, 44, 99-128.

Malec, J. (1988): Výzkum zlata a doprovodných minerálů z vybraných oblastí v Českém masivu. - Ústav nerostných surovin Kutná Hora.

Muramatsu, Y. - Wedepohl, K. H. (1998): The distribution of iodine in the earth 's crust. - Chemical Geology, 147, 201-216.

Novák, M. - Vile, M. A. - Bottrell, S. H. - Štěpánová, M. - Jačková, I. - Buzek, F. - Přechová, E. - Newton, R. J. (2005): Isotope systematics of sulfate - oxygen and sulfate - sulfur in six European peatlands. - Biogeochemistry, 76, 187-213.

Pačes, T. (1987): Hydrochemical evolution of saline waters from crystalline rocks of the Bohemian Massif (Czechoslovakia). In: Fritz, P. - Frape, S. K. (eds) Saline water and gases in crystalline rocks. - Geological Association of Canada, Special Paper, $145-156$.

Potočková, T. - Dolníček, Z. - Houzar, S. - Škrdla, P. - Vokáč, M. (2010): Primární zlatonosná mineralizace v okolí Hor u Předína, západní Morava. - Acta Musei Moraviae, Scientiae geologicae, 95, 1, 83-104.

Taylor, H. P. (1974): The application of oxygen and hydrogen isotope studies to problems of hydrothermal alteration and ore deposition. - Economic Geology, 69, 843-883.

Veselý, J. - Straka, L. - Hron, M. - Mikschi, J. - Václavek, V. - Pertoldová, J. - Malec, J. - Šimek, K. - Kopecký, P. - Obst, P. (1988): Dílčí závěrečná zpráva úkolu Český masiv - ověřování prognóz Au 0181 2101, Opatovsko-svojkovický revír. - Geofond Praha.

Veselý, J. (1992): Moravské moldanubikum. - In: Morávek, P. - Aichler, J. - Doškář, Z. - Duda, J. - Ďurišová, J. - Hauk, J. - Janatka, J. - Kalenda, F. - Klomínský, J. - Květoň, P. - Litochleb, J. - Malec, J. - Mrázek, I. - Novák, F. - Pouba, Z. - Pudilová, M. - Punčocháŕ, M. - Skácel, J. - Soukup, B. - Studničná, B. - Sztacho, P. - Šponar, P. - Tásler, R. ml. - Váňa, T. - Vaněček, M. - Veselý, J.: Zlato v Českém masivu. - Český geologický ústav, 118-120.

Vokáč, M. - Houzar, S. - Škrdla, P. (2008): Dolování zlata v širším okolí Hor u Předína na západní Moravě: dějiny výzkumů, historie dolování, topografie a archeologie lokalit a přehled geologických poměrů. - Sborník semináře Stř́brná Jihlava 2007, 1-30.

Zheng, Y. F. (1993): Calculation of oxygen isotope fractionation in anhydrous silicate minerals. - Geochimica et Cosmochimica Acta, 57, $1079-1091$. 